Hydrol. Earth Syst. Sci., 22, 5735-5739, 2018

https://doi.org/10.5194/hess-22-5735-2018

(c) Author(s) 2018. This work is distributed under the Creative Commons Attribution 4.0 License.

\title{
Joint editorial: Invigorating hydrological research through journal publications
}

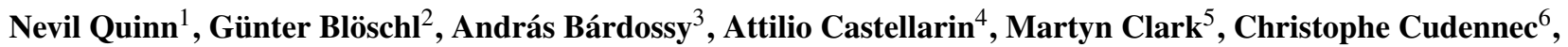 \\ Demetris Koutsoyiannis ${ }^{7}$, Upmanu Lall ${ }^{8}$, Lubomir Lichner ${ }^{9}$, Juraj Parajka ${ }^{10}$, Christa D. Peters-Lidard ${ }^{11}$, \\ Graham Sander $^{12}$, Hubert Savenije ${ }^{13}$, Keith Smettem ${ }^{14}$, Harry Vereecken ${ }^{15}$, Alberto Viglione ${ }^{16}$, Patrick Willems ${ }^{17}$, \\ Andy Wood ${ }^{18}$, Ross Woods ${ }^{19}$, Chong-Yu Xu ${ }^{20}$, and Erwin Zehe ${ }^{21}$ \\ ${ }^{1}$ Editor, Hydrology Research \\ ${ }^{2}$ Past Editor, Water Resources Research; Editor, Hydrology and Earth System Sciences; \\ Co-Editor, Journal of Hydrology and Hydromechanics \\ ${ }^{3}$ Editor in Chief, Journal of Hydrology \\ ${ }^{4}$ Co-Editor, Hydrological Sciences Journal; Associate Editor, Water Resources Research \\ ${ }^{5}$ Editor in Chief, Water Resources Research \\ ${ }^{6}$ Editor in Chief, Proceedings of the International Association of Hydrological Sciences \\ ${ }^{7}$ Co-Editor, Hydrological Sciences Journal; Editor, Hydrology and Earth System Sciences (now retired) \\ ${ }^{8}$ Editor in Chief, Water Security \\ ${ }^{9}$ Editor in Chief, Journal of Hydrology and Hydromechanics \\ ${ }^{10}$ Associate Editor, Water Resources Research; Co-Editor, Journal of Hydrology and Hydromechanics \\ ${ }^{11}$ Chief Editor, Journal of Hydrometeorology \\ ${ }^{12}$ Editor in Chief, Advances in Water Resources \\ ${ }^{13}$ Editor in Chief, Physics and Chemistry of the Earth \\ ${ }^{14}$ Editor in Chief, Ecohydrology \\ ${ }^{15}$ Editor, Vadose Zone Journal \\ ${ }^{16}$ Associate Editor, Water Resources Research; Associate Editor, Hydrological Sciences Journal \\ ${ }^{17} \mathrm{Co}$-Editor in Chief, Journal of Hydrology: Regional studies \\ ${ }^{18}$ Editor, Journal of Hydrometeorology \\ ${ }^{19}$ Co-Editor, Hydrological Sciences Journal \\ ${ }^{20}$ Editor, Hydrology Research \\ ${ }^{21}$ Chief Executive Editor, Hydrology and Earth System Sciences
}

Correspondence: Nevil Quinn (nevil.quinn@uwe.ac.uk)

Received: 31 July 2018 - Published: 5 November 2018

\begin{abstract}
Editors of several journals in the field of hydrology met during the General Assembly of the European Geosciences Union (EGU) in Vienna in April 2017. This event was a follow-up of similar meetings held in 2013 and 2015. These meetings enable the group of editors to review the current status of the journals and the publication process, and to share thoughts on future strategies. Journals were represented at the 2017 meeting by their editors, as shown in the
\end{abstract}

list of authors. The main points on invigorating hydrological research through journal publications are communicated in this joint editorial published in the above journals. 


\section{Introduction}

Over the past five years, the editors of a number of journals in the discipline of hydrology have met informally to discuss challenges and concerns in relation to the rapidly changing publishing landscape. Two of the previous meetings, in Gothenburg in July 2013 and in Prague in June 2015, were followed by joint editorials (Blöschl et al., 2014; Koutsoyiannis et al., 2016) published in all participating journals. A meeting was convened in Vienna in April 2017 (during the General Assembly of the European Geosciences Union EGU) which was attended by 21 editors representing 14 journals. Even though the journals are published in quite different settings, the editors found common cause in a vision of the editor's role beyond just that of gatekeeper ensuring high-quality publications, to also being critical facilitators of scientific advances. In that enabling spirit, we as editors acknowledge the need to anticipate and adapt to the changing publishing landscape. This editorial communicates our views on the implications for authors, readers, reviewers, institutional assessors and the community of editors, as discussed during the meeting, and subsequently.

\section{Recent trends in the publication process - quantity, speed and multiple authorships}

The previous joint editorials have reflected on the increased productivity across the discipline, and more broadly in science, as evidenced by a rise in manuscript submissions. This growth in submissions and publications has continued in recent years at an unfaltering rate. Collectively, the 14 journals represented in this editorial published 46000 pages in 2017, compared with only 26000 pages a decade earlier. The main driver of increased submissions has been intensified publication pressure, which has given rise to a number of trends of concern that privilege quantity over quality of science: in "salami publishing" (Martin, 2013; Koutsoyiannis et al., 2016) authors split a body of work into several papers in order to increase the number of their publications and their citation counts. There is also a tendency to publish work prematurely, where the contribution is incremental rather than significant. Despite the standard use of plagiarism detection tools by most journals, plagiarism still does occur, and "recycling", where authors repackage their own work with minimal extension for a different audience, is on the increase. Some of this would be regarded as self-plagiarism (Martin, 2013). There have been cases of authors submitting the same manuscript simultaneously to multiple journals, and authors immediately submitting a rejected manuscript to another journal without any reflection or revision in response to reviewer evaluations. There are also instances of reviewers (and editors) attempting to promote their own (or their journals') citation metrics by requiring authors to cite their list of papers (citation coercion and citation stacking). None of these practices are conducive to advancing the science of hydrology. On the contrary, they contribute to a system overload and a dilution of useful information in the published literature.

Another trend that has become acute recently is that of a push towards speedier publication. New media have created a culture of immediacy for traditional journals (Brossard and Scheufele, 2013), and editors are under pressure to reduce turn-around times, both in relation to time to first decision and the subsequent review process. Most hydrology journals have reduced their turn-around times by at least two months in the last decade, little of which can be attributed to technical and system improvements. A number of journals have introduced a "fast-track" or "rapid communication" route in an attempt to report quickly on an extreme event or new technology. These types of papers place a higher burden on reviewers in relation to speed and additional challenges to editorial teams regarding review quality, while authors risk compromising quality for expediency. Recent experience has highlighted the additional risks of premature press releases, where a paper is subsequently rejected but broadcasters have already acted on a press release. Various approaches to providing a "fast-track" stream are being considered by hydrology journals, with varying degrees of success. As a discipline we need to reflect on whether these approaches are consistent with the notion of high-quality communication in our journals or whether other communication forms (e.g. newsletters, professional magazines, new media) might be more appropriate. It may well be that different approaches may coexist within hydrology.

The third, conspicuous trend is that of an increase in the number of authors per paper. In the 1980s, the average number of authors per paper of hydrological journal articles was below 2 while this figure has soared to 4 to 5 in 2017, depending on the journal. While European Research Council (ERC) and other internationally funded research often necessarily involve multiple authorships, this does make an individual's contribution difficult to determine and advantages "networkers" as much as "true contributors". Although long author lists are evidently not negative per se, as they demonstrate the need for collaboration and integration of specialized knowledge, they may be problematic when used for research assessments. Koutsoyiannis et al. (2016) suggested addressing this issue by normalizing citation statistics by the number of authors. There have been similar discussions in other disciplines. In medicine, for example, a new approach to authorship transparency has been formalized through the CRediT (Contributor Roles Taxonomy) initiative (see http: //docs.casrai.org/CRediT, last access: 2 November 2018, and McNutt et al., 2018). While the discipline reflects on ways of dealing with this challenge, we recommend that, in the interim, multi-authored research papers should include a statement of attribution of contributions, specifying who of the author list contributed in designing the research, conducting the research, writing the text, editing the text and funding 
the research. Furthermore, these trends are located within a changing landscape of academic publishing. Research funders and users of research outputs are increasingly demanding open access, and publishers are grappling with different models. This adds additional complexities to the issues of quantity, speed and multiple authorships.

\section{Recognizing importance of novel insight}

The main purpose of scientific publication consists of communicating new, important findings to peers in order to advance the science. The main role of editors, together with authors, reviewers and associate editors, is to maximize the potential towards fostering progress. During the publication process, the degree to which the manuscript contributes to advancing our science is in theory detected by the peer review system. However, as publications become more numerous, models more complex and data sets more extensive, it has sometimes become very difficult to assess the validity of a new theory or model prediction on the basis of the material contained in a manuscript. Most hydrology journals have therefore adopted a policy of open data and open models (e.g. Data Citation Synthesis Group, 2014), to allow peers - at least in principle - to repeat any published study. While the open data/model policies are recognized as being important, there are particular challenges in hydrology as, in some countries, the data (and models) used are often proprietary. Also, publication strategies often involve keeping part of the data for further analyses by the same group. Open data/model policies will certainly need particular attention in the near future and will likely require a change in the thinking of researchers and data collection agencies. Given the increasing burden that open data and open model policies impose on authors, institutions and journals should seek approaches that facilitate compliance.

A secondary purpose of scientific publication lies in recognizing the contributions of individuals and their research institutions. While, traditionally, this was done by attributing seminal achievements to the authors publishing them (e.g. Newton became famous through the power of ideas in his Principia), the process has today become more formalized due to the availability of publication databases and associated metrics. Typical assessment criteria are the number of publications, the citations they receive, and the quality of the journals in which they are published.

The quality of journals, as used in research assessments, is often quantified by journal impact factors (IFs). They are a measure of the number of citations to the papers of that journal over a particular period and have been used to separate reputable journals from low threshold web postings, new media and predatory journals (Beall, 2016). The presumption is that the quality of individual papers can somehow be inferred from the citation count of the journal as a whole. A comparison among six leading hydrology journals over the period 1996 to 2016, published as an editorial in Water Resources Research (Clark and Hanson, 2017), concludes that the journal impact factor in a given year does not have much predictive power for journal-level productivity. Impact factors, particularly in smaller journals, were found to vary substantially across years, which can be expected for statistical reasons (small samples). This is not to say that a journal's impact factor is not a useful metric; with many more journals appearing, an impact factor could be helpful, for example, in indicating journal development and maturity. The important point is that assessments of research quality and choices of journals for submitting work to should not be driven by impact factors. Furthermore, a comparison between disciplines suggests that the journal impact factors of hydrology journals are rather low (all journals reviewed have an impact factor of less than 5; Clark and Hanson, 2017) in relation to disciplines such as medicine, chemistry and physics, which highlights the problem of using impact factors to compare the quality of work across disciplines (Koutsoyiannis and Kundzewicz, 2007). In hydrology, papers tend to be cited over much longer time periods which, together with the smaller size of the discipline, means that the short 2-year time window for impact factor calculation is a limitation in our discipline. It is also influenced by the fact that impacts of some hydrological publications materialize through application to water-related management, which is not reflected in citations (Cudennec and Hubert, 2008).

It is arguable whether there is any set of metrics that would effectively measure a lasting contribution to academic thought and practice, quite apart from whether these could be gamed by an individual choosing to do so. A general concern therefore emerges from the current practice of assessing and ranking scientific productivity of institutions, journals and individuals by bibliometric indices which could indirectly incentivize academic misconduct (Edwards and Roy, 2017). We also note that the San Francisco Declaration on Research Assessment (DORA) (http://www.ascb.org/dora/, last access: 2 November 2018) urges a focus on the scientific contribution of published papers rather than where the papers were published in an attempt to reduce the misuse of impact factors for research assessment. Similarly, the commendable EU "Open Science" initiative and associated report on next generation responsible metrics (https://ec.europa.eu/ research/openscience/pdf/report.pdf, last access: 2 November 2018) should inform our debate and practice. It would stand hydrology in good stead if we, like only a generation ago, assessed research impact (and the performance of individuals and institutions) by the changes in the thinking induced, rather than by citation numbers. This is the (unfortunately not objectively measurable) criterion that would maximize advances in science, suggesting that peer review assessments should be given higher priority in the future. 


\section{Role of journals in setting the science agenda}

With climate change currently being high on the political agenda and coupled with prevailing publication pressures, it is not surprising that submissions on climate impact studies, often with little novelty or innovation, have become something of a cottage industry. Equally disappointing is the proliferation of model applications with marginal innovation and/or little generality. There is indeed an interesting question of whether societal needs, fundamental ideas or new technologies are the main drivers of scientific progress. Sivapalan and Blöschl (2017) suggested that all three have been and will be important ingredients in hydrology. They also noted that research progress has come about in discrete steps or "eras". For example, the two decades from 1970 to 1990 focused on hydrological processes involving substantial field work. Later the interest in field work ebbed away because of the high cost-to-benefit ratio (Blume et al., 2017) and changing societal priorities.

Indeed in the 21 st century the human footprint is fast becoming a dominant feature in the hydrological cycle, and research across the disciplines is becoming mandatory. Publishing interdisciplinary research, however, still remains challenging. There is a tendency for researchers and their communities to be socialized within their own discipline niches, and communities may become self-reinforcing to the detriment of fresh outside perspectives. Most hydrology journals have already responded strategically to these interdisciplinary publication needs, for example, by selecting editors and reviewers from a diverse set of disciplines. The strategic response of Water Resources Research (WRR) is a potential approach to help mature interdisciplinary thinking. WRR encourages didactic reviews to provide the perspective of other disciplines (i.e. how they undertake research and engage discourse within their field) and also commentary papers that explore why a particular field is struggling and seeks to explore the field from multiple perspectives.

Whether the research is disciplinary or inter-/multidisciplinary, journals play an important role in communicating and setting the trend for the vision of hydrological research, and for fostering innovation in a coherent way. We need to work collectively to ensure that science of the highest quality and that innovative content is published in our journals. To do this the hydrological community must redress research investment deficiencies and the publication biases that arise as a result of a lack of funding. Research agendas should not be so narrowly linked to today's problems, and we need to be bold in setting out the grand challenges of our discipline. For example, the International Association of Hydrological Sciences (IAHS), in collaboration with the Hydrology Divisions of EGU and AGU, has recently called for compiling a list of unsolved scientific problems in hydrology that would invigorate research in the 21 st century (https: //iahs.info/IAHS-UPH/, last access: 2 November 2018). The initiative has been motivated by David Hilbert's (1900) un- solved problems, which have greatly stimulated focused research in mathematics. The idea is that a similar list of problems could be identified by the hydrological community. For tangible progress to be made the problems should be framed so they

- ideally relate to observed phenomena and why they happen

- are universal (i.e. not only apply to one catchment or region)

- are specific (so there is hope they can be solved).

We commend this initiative and urge colleagues to contribute to shaping progress in hydrology.

\section{Summary and concluding remarks}

Hydrology, a traditionally integrative science with high societal relevance and geographic diversity, is perhaps an optimal place from which to launch the movement to reassert the academic spirit in a time where there is dramatic change in the way people learn, synthesize and interact with each other. Our community stands at the cusp of perhaps the greatest societal revolution in the democratization of access to resources and knowledge, as well as to the largest population the world has ever seen. These societal and technological changes have major effects on the publishing landscape. For hydrological journals there is a unique opportunity to learn through harnessing the energies of the moment to continue to improve our concept of the world and the role water plays in it.

- Publication quantity, speed and multiple authorships. Authors, reviewers and editors are encouraged to prioritize research quality over quantity. Discussions are currently under way to discourage unethical behaviour of authors, reviewers and editorial board members. Measures may involve a system for sharing information on ethical misconduct across hydrology, in addition to reinforcing the guidelines of COPE (Committee of Publication Ethics), to which our journals adhere. Authors are encouraged to make a personal judgement on whether fast-track findings may be more appropriately communicated through scientific journals or other communication forms. Similarly we must emphasize transparency in authorship contributions; multi-authored papers should include a statement of attribution of the individual contributions.

- Recognizing importance of novel insight. Most hydrology journals have adopted a policy of open data and open models, to allow peers to repeat any published study and fully appreciate the validity and novelty of the material. For these policies to be fully embraced, a change in culture will be required by both researchers 
and data collection agencies. The issue of research assessment on the basis of impact factors (the "tyranny of metrics") (Delzon et al., 2016) is symptomatic of a larger problem that we need to address and act on; the core values of transparency and peer review are the foundations of the scientific and social capital of our journals, and these principles, combined with embracing alternate and still-to-emerge media, will ensure that journals remain the trusted and authoritative communications outlets for compelling ideas for, and of, the future. We need to identify ways of ensuring that the value of hydrological journals continues to be recognized; we need to ensure that they are a primary and effective forum for furthering the science and practice of hydrology, and presenting solutions to challenging problems. We also need to ensure the focus of research assessments is on the scientific contributions of individual journal papers rather than on impact factors.

- Role of journals in setting the science agenda. Journals play an important contributory role - together with their parent organizations and associated conferences - in communicating and setting the trend for the vision of hydrological research, and for fostering innovation in a coherent way. Research agendas should be forward looking and not be narrowly linked to today's problems. There is a need for the discipline to work collectively to redress such funding and publication biases that consequently arise. We need to ensure that science of the highest quality and innovative content that facilitates and invigorates hydrological research is published in our journals.

As a hydrological community we are experiencing unprecedented challenges emerging from the rapidly changing science communication landscape. These challenges also represent an opportunity for a renaissance in the scope and societal impact of our discipline. As we engage with new modes of communication, we must remain vigilant to ensure top-quality science distinguishes our journals from the mass of unverified online information. The success of new measures for author transparency, for reducing scientometric bias, and for reinvigorating the hydrological science agenda depends on your participation and engagement. To realize this renaissance, we urge all to act in support of the issues raised in this editorial through activities within journal institutions, professional societies and the broader community of practice.

Acknowledgements. This editorial has benefited from the insightful critique of three reviewers - Dani Or, Murugesu Sivapalan and Ian Littlewood - and we would like to extend our collective thanks to these reviewers for their useful perspectives, comments and additions.

\section{References}

Beall, J.: Essential information about predatory publishers and journals, International Higher Education, 86 (Summer 2016), 2 pp., https://doi.org/10.6017/ihe.2016.86.9358, 2016.

Blöschl, G., Bárdossy, A., Koutsoyiannis, D., Kundzewicz, Z., Littlewood, I., Montanari, A., and Savenije, H.: Joint editorial - On the future of journal publications in hydrology, Hydrol. Res., 45, 515-518, https://doi.org/10.2166/nh.2014.006, 2014.

Blume, T., van Meerveld, I., and Weiler, M.: The role of experimental work in hydrological sciences-insights from a community survey, Hydrolog. Sci. J., 62, 334-337, https://doi.org/10.1080/02626667.2016.1230675, 2017.

Brossard, D. and Scheufele, D. A.: Science, new media, and the public, Science, 339, 40-41, https://doi.org/10.1126/science.1232329, 2013.

Clark, M. and Hanson, R.: Editorial - The citation impact of hydrology journals, Water Resour. Res., 53, 4533-4541, https://doi.org/10.1002/2017WR021125, 2017.

Cudennec, C. and Hubert, P.: The multi-objective role of HSJ in processing and disseminating hydrological knowledge, Hydrolog. Sci. J., 53, 485-487, https://doi.org/10.1623/hysj.53.2.485, 2008.

Data Citation Synthesis Group: Joint Declaration of Data Citation Principles, edited by: Martone, M., San Diego CA, FORCE11, 2014.

Delzon, S., Cochard, H., and Pfautsch, S.: Indexing the indices: scientific publishing needs to undergo a revolution, Journal of Plant Hydraulics, 3, e009, https://doi.org/10.20870/jph.2016.e009, 2016.

Edwards, M. A. and Roy, S.: Academic research in the 21st century: Maintaining scientific integrity in a climate of perverse incentives and hypercompetition, Environ. Eng. Sci., 34, 51-61, https://doi.org/10.1089/ees.2016.0223, 2017.

Hilbert, D.: Mathematische Probleme, Nachrichten von der Königlichen Gesellschaft der Wissenschaften zu Göttingen Mathematisch-Physikalische Klasse, 253-297, 1900.

Koutsoyiannis, D. and Kundzewicz, Z.: Editorial - Quantifying the impact of hydrological studies, Hydrolog. Sci. J., 52, 3-17, https://doi.org/10.1623/hysj.52.1.3, 2007.

Koutsoyiannis, D., Blöschl, G., Bárdossy, A., Cudennec, C., Hughes, D., Montanari, A., Neuweiler, I., and Savenije, H.: Joint editorial - Fostering innovation and improving impact assessment for journal publications in hydrology, Hydrolog. Sci. J., 61, 1170-1173, https://doi.org/10.1002/2016WR018895, 2016.

Martin, B.: Whither research integrity? Plagiarism, Selfplagiarism and coercive citation in an age of research assessment, Res. Policy, 42, 1005-1014, https://doi.org/10.1016/j.respol.2013.03.011, 2013.

McNutt, M., Bradford, M., Drazen, J., Hanson, B., Howard, B. Jamieson, K., Kiermer, V., Marcus, E., Pope, B., Scheckman, R., Swaminathan, S., Stang, P., and Verma, I.: Transparency in authors' contributions and responsibilities to promote integrity in scientific publication, P. Natl. Acad. Sci. USA, 115, 2557-2560, https://doi.org/10.1073/pnas.1715374115, 2018.

Sivapalan, M. and Blöschl, G.: The growth of hydrological understanding: Technologies, ideas, and societal needs shape the field, Water Resour. Res., 53, 8137-8146, https://doi.org/10.1002/2017WR021396, 2017. 